\title{
Cultural Aspect of Interaction Design beyond Human-Computer Interaction
}

\author{
Rungtai Lin ${ }^{1}$, Po-Hsien Lin ${ }^{1}$, Wen-Shin Shiao ${ }^{1}$, and Su-Huei Lin ${ }^{2}$ \\ ${ }^{1}$ Crafts and Design Department, National Taiwan University of Art \\ Ban Ciao City, Taipei 22058, Taiwan \\ rtlin@mail.ntua.edu.tw \\ ${ }^{2}$ Department of Fashion Imaging, Mingdao University \\ Peetow, Changhua 52345, Taiwan \\ eric@mdu.edu.tw
}

\begin{abstract}
Over the past several decades, we have made many efforts to understand Human-Computer Interaction (HCI). But beyond HCI, we need a better understanding of Human-Culture Interaction not just for taking part in the cultural context, but also for developing the interactive experience of users. Therefore we propose a general framework for cultural product experience that applies to the mental models of designer and user and which can be experienced in Human-Culture Interaction. Then, based on the interactive experience of users with an aboriginal cultural object, the Linnak (a twin drinking cup), a modern Linnak was proposed to demonstrate how to design a successful cultural product using the human-culture interaction framework. The intended purpose of this paper is to provide a framework for examining the way designers interact across cultures and the interactive experience of users in the design process.
\end{abstract}

Keywords: Interaction Design, User Experience, Cultural Product Design.

\section{Introduction}

The growth of interest in human-computer interaction (HCI) over the past decades has been extraordinary, and it is one of the most rapidly developing subjects in the field of computer science and human factors. HCI became a fascinating research subject and is now recognized as a vital component of successful computer applications $[4,17]$. Over the past several decades, researchers made great efforts to understand HCI. Based on scientific research and development, we know a great deal about creating successful human - computer interaction. The influence of HCI science in interaction design plays an important role in product design and development, especially for information technology products. The multidisciplinary development of HCI has advanced many research and design models. In designing products with embedded information technologies, the role of HCI is a basic, fundamental consideration. As such, the challenge exists of regarding the development of mature HCI research and its impact on design and investigating what dimensions beyond HCI will be exploited in increasingly transforming our lives at home and at work [4, 18, 19]. 
Recently, Kansei engineering has gained popularity and broad application in human product interaction design. Kansei engineering is a design method developed to construct relationships between user experiences and product properties in order to use these properties to design products that fulfill a user's desired experiences $[1,20]$. Desmet \& Hekkert [2] had mentioned that experience is not a property of the product but the outcome of human-product interaction and the results depend on what temporal characteristics and product experiences the user brings into the interaction. Therefore, this study intends to combine Kansei engineering and affective design to explore the Human-Culture Interaction beyond HCI.

Interaction design has switched focus from usability and cognitive ergonomics to the affective and interactive experience of users. Culture plays an important role in products with embedded information technologies, and designing culture into products will become a design trend in interactive design. Beyond HCI then, we need a better understanding of Human-Culture Interaction not just for taking part in the cultural context, but also for developing the interactive experience of users. With technical advances, HCI has also advanced phenomenally over the last ten years [17]. In addition, HCI has extended our understanding of interaction with information technology products and how to put this understanding to practical use in the design and evaluation of daily used products. The concept is supported by Shneiderman [21] who noted that we are now in the second transformation of computing, in which the shift from machine-centered automation to user-centered services and tools, is enabling users to be more creative. The HCI design process asserts that the architecture of system and interface components should be directed by a holistic understanding of "use and user needs through a process of intelligent and conscious design." [7,3].

Norman [15] argued that affect and emotion are not as well understood as cognition, but are both considered part of the information processing system with different functions and operating parameters. Therefore, we propose a general framework for cultural product experience that applies to the mental model of designer and user and which can be experienced in Human-Culture Interaction. Then, based on the interactive experience of users with the aboriginal cultural object, Linnak (a twin drinking cup), a modern Linnak was proposed to demonstrate how to design a successful cultural product using the human-culture interaction framework. The intended purpose of this paper is to provide a framework for examining the way designers interact across cultures and the interactive experience of users in the design process.

\section{Cultural Product Design Model - Linnak as the Example}

Using Cultural features to add extra value to a product can benefit not only economic growth, but also promote unique local culture in the global market. Therefore, because transferring cultural features into a cultural product becomes a critical issue, a cultural product design model including three main parts: conceptual model, research method, and design process, was proposed for combining culture levels, layers, and design features which facilitate understanding cultural product design [11,12].

In Lin's paper [11], the "Linnak", a twin-cup, was chosen as the cultural object to transfer its cultural features into a modern product. After its appearance, usability, and cultural meaning were studied, the usage behavior and meaning of "sharing with each 
other" was identified. The "Eternity", a modern twin-cup shown in Figure 1, was proposed to show the culture meaning of "sharing with each other" from the original cultural object - the Linnak. The "Eternity" is a symmetrical pair of cups connected together inversely to show the close relationship of the drinkers as a couple. This design won the gold award at the "2006 5th Bombay Sapphire Designer Glass Competition Taiwan," and was chosen to enter the global competition that takes place each April in Milan, Italy, during the Salone del Mobile, the world's biggest design fair.

The "Eternity" was designed as an interactive modern product to be used for example in a night club. In the use scenario shown in Figure 2 [11], a man wanting to develop a relationship with a lady, treats her with wine in the drinking cup. The design concept constituted the communication with man to woman and the drinking behavior became the mid-level relation. In the inner level of the Linnak, "sharing with each other" is transformed to communication with each other. It was romance that used the cultural object for modern social behavior.

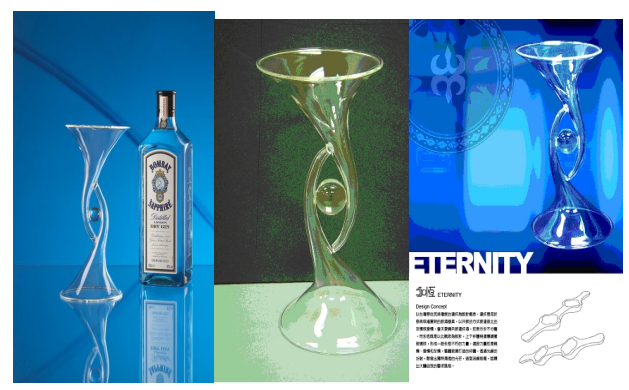

Fig. 1. The Eternity - a modern twin cup

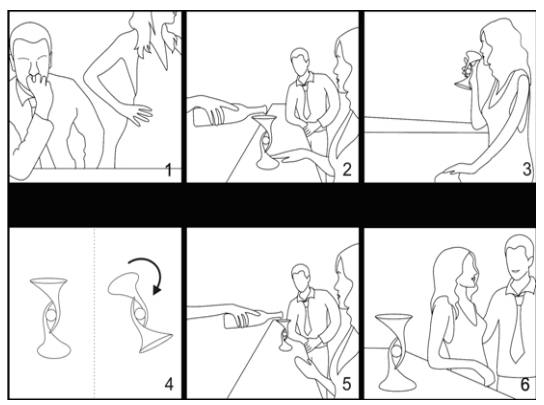

Fig. 2. The scenario of Eternity

\section{Framework for Human - Culture Interaction}

Taking the "Eternity" as an example, the "Linnak" is a typical cultural object which can be transformed into a contemporary design for the current consumer market. There are social meanings, ergonomic concerns and functional achievement associated with this cultural object. To provide an ideal drinking cup for the modern market, both the social 
and operational interfaces of the "Linnak" need to be well-designed. However, the contemporary consumer market may need a new form of the "Linnak" suitable for the modern environment. Thus, how to communicate with the "Linnak" and extract the idea of "sharing with each other" in the design of the "Eternity" are valuable for enhancing usage in our daily life [11]. Based on the previous studies and Norman's conceptual models [15], a framework of Human-Culture Interaction (Figure 3) was proposed for examining the way designers communicate across cultures as well as the cultural aspect of interaction and user experience in the design process.

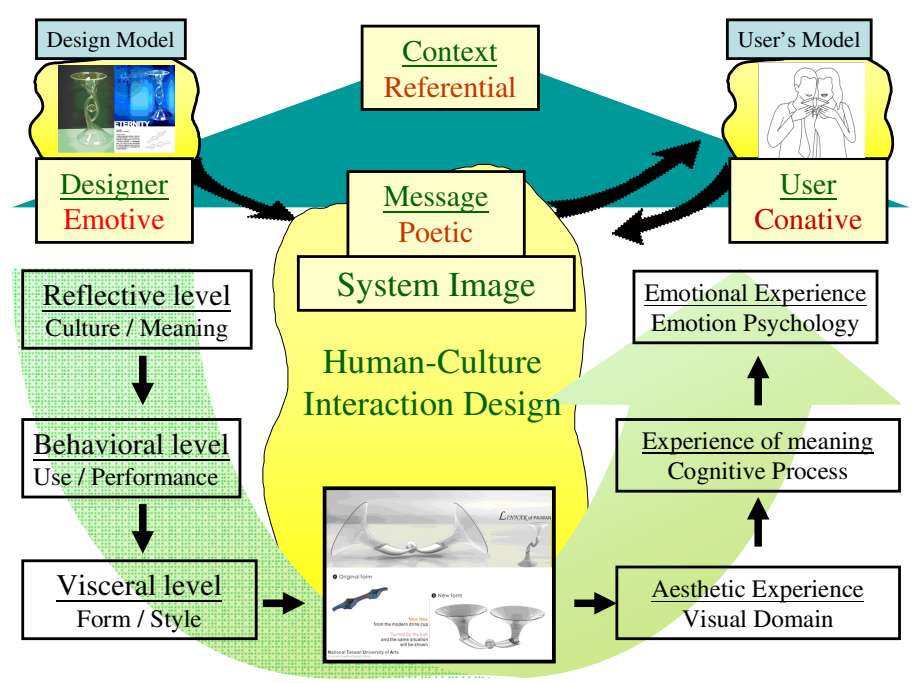

Fig. 3. The Human-Culture Interaction Model

For the design model, the designer focuses on the analysis of cultural meaning, operational interface, and the scenario in which the cultural object was used. System image results from the cultural features that have been redefined in order to design a cultural and aesthetical product. The user's model is the mental model developed through interaction with the cultural product. Based on the cultural context, the designer expects the user's model to be identical to the design model through the culture aspect of interaction design.

For the designer's conceptual model, there are three levels of processing including: visceral, behavioral, and reflective design. Using the "Eternity" as an example, the design features of "Linnak" has been identified with three levels of cultural features: (1) reflective design (inner-level) focuses on the cultural meaning of "making friendship", "working together", and "sharing with each other."; (2) behavioral design (mid-level) focuses on the consumer behavior and the scenario in which people will use the "Linnak" on various occasions; and (3) visceral design (outer-level) focuses on the "Linnak" form factors which are associated with material, colors, texture, and pattern $[9,10,11,15]$.

For the user's model, the user communicates directly with the cultural product. If the cultural product does not make the culture meaning clear and attractive, then use will 
end with the wrong message during the human-product interaction. There are also three levels of human-product interaction: aesthetic experience, experience of meaning, and emotional experience. The aesthetic experience involves a cultural product's form, color, texture etc., to delight the user's sensory modalities. The experience of meaning involves the user's ability including operation, safety etc., to assign the design features and assess user pleasure with the cultural product. The emotional experience involves user emotion including self-image, personal satisfaction, memories etc., which are elicited by the cultural objects and designed into the cultural product.

Based on communication theory, according to Jackson's model [6], a designer sends a message to a user via the cultural product. The designer recognizes that this cultural product must refer to something other than itself which is called the culture context. The emotive function is to communicate the designer's emotions which extract from a cultural object all those elements that make its meaning unique. The other end of the process is the conative function which refers to the affection produced in the user by the cultural product. The referential function is the most important part of human-product interaction in culture meaning of the cultural product. The framework indicates how to extract the cultural features for designing a cultural product. These features underlie the different conceptual models of cultural product experiences which are used to explain the process and culture meaning of human-culture interaction.

\section{Ergonomic Considerations for Human Product Interaction}

The most important ergonomic consideration for designing daily-life products is "designing for human use", especially when addressing the issue of applying anthropometric data. In ergonomic considerations, the requirement in anthropometric design is to determine a value for some design parameter in terms of a percentile cutoff for an anthropometric value in order to meet a target percentage for a population of interest. The anthropometric database is used as a design reference for daily used products. However, the most effective application of such data in product design is another important issue $[13,14]$.

The "Linnak" ranges in length from $43 \mathrm{~cm}$ (low percentile) to $91 \mathrm{~cm}$ (high percentile). Its average length is about $74.4 \mathrm{~cm}$ (50 percentile). In addition , the average width and height of the twin cup are $11 \mathrm{~cm}$, and $7.3 \mathrm{~cm}$ respectively. The distance between the center of two cups varies from 29 to $42 \mathrm{~cm}$, and the capacity is about 600 c.c.. These dimensions have indicated the way in which this cultural object was used and these distances indicated an invisible space between two people. From a usability point of view, the diamond shape cup illustrates that an angular mouth was used for ease of drinking wine. Furthermore, the drinking process has emphasis the meaning of "working together" and "sharing with each other."

After reviewing the literature and studying the drinking situation, two kinds of drinking situations were found to be most common with the aborigine twin cup. When it is used in special situations (e.g. wedding ceremony), the couple or the intimacy will be as shown in the top of Figure 4. That was the close face-to-face mode showing an intimate close relationship. When the twin cups are used in the normal situation, people drink the wine together to demonstrate their friendship, and the drinking situation will be shoulder to shoulder as shown in the bottom of Figure 4. 


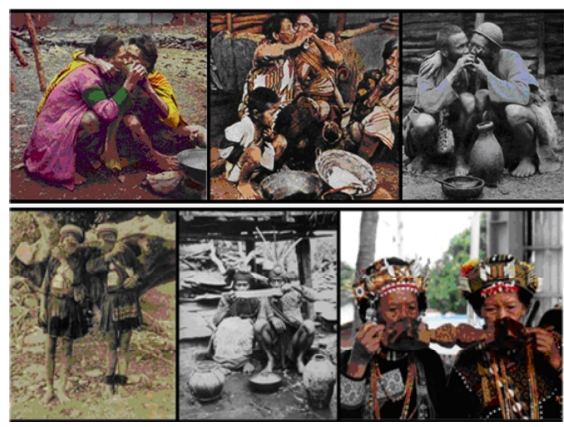

Fig. 4. Drinking in the close relationships

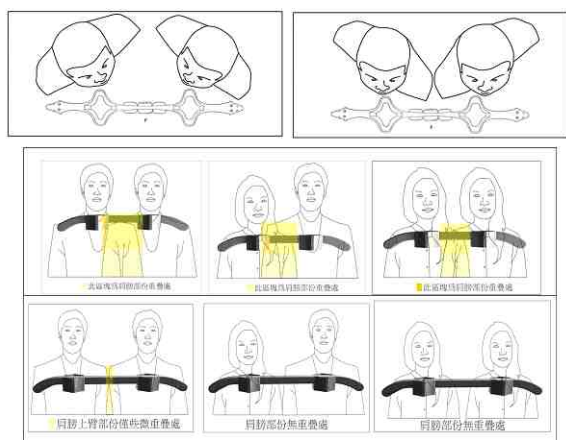

Fig. 5. The simulation of drinking situations

When applying anthropometric data, three anthropometric design principles must be considered: extreme individuals, an adjustable range, and the average. For example, using the average size twin cups, the results showed that the users' heads would not be touched to each other while they are drinking but their shoulders would. In this situation, they will not feel uncomfortable about their body. Figure 5 shows the simulation of drinking postures under different situations.

\section{Testing Interactive Experience of a Cultural Product}

Using anthropometric data in design involves art as well as science. However, in the use of such data for designing daily-life products, there are generally two aspects: 1) determine what anthropometric design principle should be applied, and 2) achieve the anthropometric considerations in the most cost effective manner. Based on these principles, the recommendations of ergonomic dimensions for the ideal twin cup were studied. Therefore, this study focused on the application of anthropometric data by collecting the suitable dimensions of twin cups. Then the minimum, the average, and the maximum sizes were chosen as the examples and three kinds of model were built and used as samples to test the operation of a "Linnak." as shown in the Figure 6. 


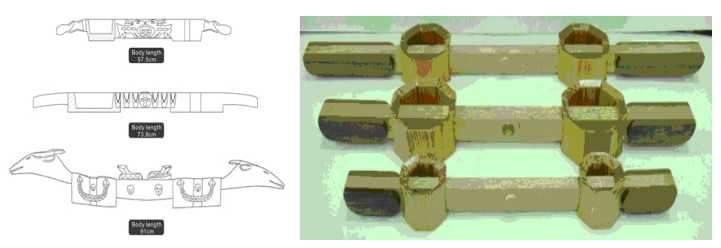

Fig. 6. Three kinds of wooden models as test samples

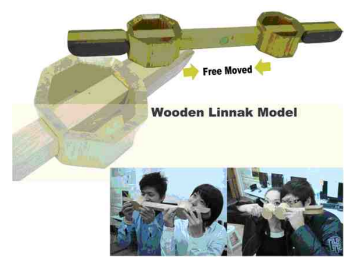

Fig. 7. The Experimental Situation

Using the wooden Linnak models, an experiment was conducted to explore the operation of user experience. In the experiment, the two cups can be moved by the participants to form the most agreeable situation (Figure 7). 40 students who are 20 couples of intimacy served as the subjects. Subjects were told the purpose of the study. A PowerPoint presentation was prepared to introduce the cultural meaning and use scenario of the Linnak to the participants. Then they were asked to used the Linnak model for simulating the drinking situation and exploring the preference gesture in drinking. Finally, they were asked to answer a subjective questionnaire about their user experience.

Using user experience information, the communication between a cultural object and its users has been studied. For designers following the "Cultural Product Design Model", the important consideration of the design elements had been extracted from the culture meaning. Thus the user experience related to the cultural object followed the human-culture interaction model [11].

\section{Designing "Friendships" into the "Eternity"}

In Lin's study [11], the "Eternity" demonstrates the value of Aboriginal culture in design. After the paper was published, some comments came from many readers arguing the loss of the culture meaning of "sharing with each other". In Figure 2, the use scenario of "Eternity" in the night club indicated that the "Eternity" lost the culture meaning of close relationships when two people are not drinking at the same time. For example, Norman's personal communication stated that:

"I still very much like the Linnak cup in which the two people drink at the very same time, side by side. I am afraid that this behavior has been lost with the "Eternity": With Eternity, the two people have to drink one at a time - this is very different. I wonder if your students would explore this difference?" 
These comments emphasize the cultural aspect of human-culture interaction design, therefore, designing the culture meaning of "sharing with each other" into the "Eternity" became an important issue in the cultural product design process. Following the scenario of using "Eternity" at a night club (Figure 2), in which the man wants to develop a relationship with a lady using just the standard form of "Eternity", subjects communicated developing a relationship with their friends. When the "Eternity" bridges close relationships, then the next step is to use the ball (in the middle of two cups) as pivot and turn the bottom cup to a traditional Linnak as shown in figure 8. At this time, the couple can drink together at the same time, side by side, shoulder by shoulder, or even face to face to show how intimate they are!

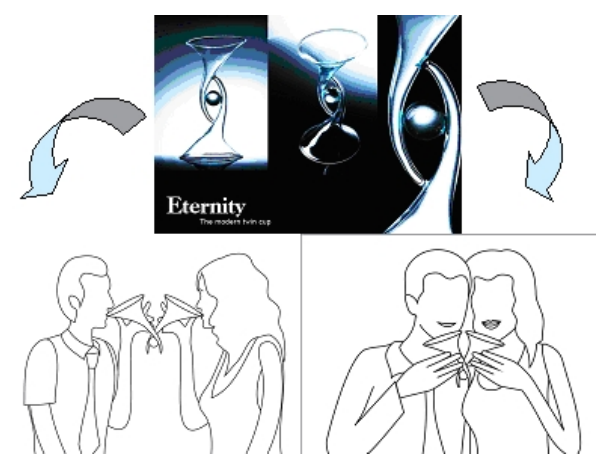

Fig. 8. The concept of drinking together using "Eternity"
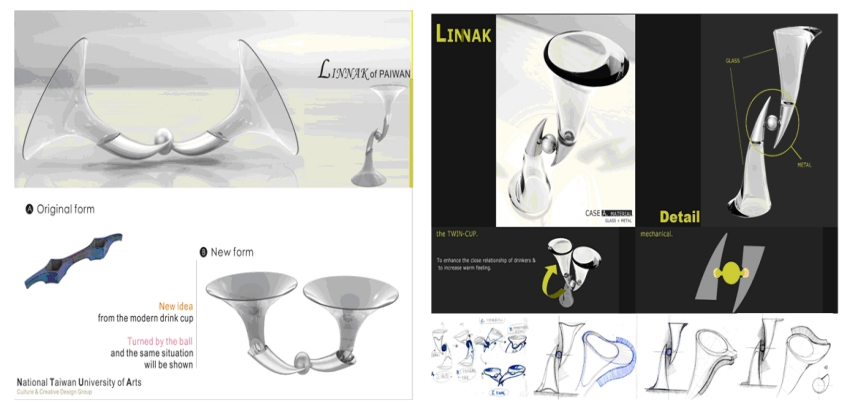

Fig. 9. The redesign of "Eternity" in case A and B

Based on the structure of the "Eternity" and the user experience and comfort considerations, the refined version of designing "close relationships" into "Eternity" was developed. The design case A is shown in the left of Figure 9. A special joint device was designed for transforming three usage forms - the standard form of cups up and down; the turning form via the rolling ball; and the two cups side by side. In testing user experience, the users stated that "positive relationship with the partner will make them take the two cups closely." According to user response, a metal device joining the glass-body of cups was proposed to transform the cup form and fit the different relationships and 
drinking situations. Figure 9 (right) shows design case B. The rolling ball device for transforming to fit different drinking situations was retained. For usability considerations, design case $\mathrm{B}$ added the new handle part at the side of the cup edge, and made the edge of cup thick and solid to become the holder.

\section{Conclusion}

"Culture" plays an important role in the interaction design field and has been considered a key design evaluation point for the future. Designing "culture" into products will be a design trend in the global market. The importance of studying culture in human product interaction design is shown repeatedly in several studies in all areas of technology design. In addition, HCI considerations in system design continues to progress, and in the field of interaction design between human and product especially, the cultural aspect of interaction design and affective interactive experience of users will be more broadly used. Therefore, this paper proposed a framework of human culture interaction that shows how the cultural aspect of interaction design would be developed in the field of human interactive design beyond the human-computer interaction process.

The culture of drinking wine is a very common social event in human society around the world, and it presents the emotional communication of user experiences. With the primitive behavior of human beings, the social events of drinking wine culture proceeded constantly and wine related products became popular daily products in the design fields. The "Eternity" presented in this study provides a good example of applying cultural features to interaction design while still retaining a meaningful cultural value. Taking "Eternity" as an example, this paper demonstrated the cultural features of "Linnak" found in three culture levels and how to transform those cultural features of interactive experiences into a new cultural product design which can fit into the contemporary market.

The framework of human-culture interaction that was proposed in this paper provides a different way of thinking about interactive experiences with acculturation. The acculturation process is the exchange of features that are composed of the traditional culture, cultural features, cultural objects, interface design, interaction experience, user emotion, and user response [8]. The most important part of this process is the user experience added in the cultural product design process and involved Kansei engineering considerations. The framework is of value for designers because it can help to design "culture features" into interaction design, as well as provide users with a valuable reference for understanding interactive experience.

For future studies, we need a better understanding of the acculturation process not only for the designer's model, but also for that of the user's. While cultural features become important issues in the interactive experiences of users, the acculturation process between human and culture becomes a key issue in the cultural product design and are worthy of further in-depth study.

Acknowledgments. The authors gratefully acknowledges the support for this research provided by the National Science Council under Grants No. NSC-96-2221-E-144-001. The author also wishes to thank the various students who designed the products 
presented in this paper, especially, C. H. Hsu, H. Cheng, M. X. Sun, and E. T., Kuo, and colleagues who have contributed to this study over the years, especially, Dr. J. G. Kreifeldt.

\section{References}

1. Chang, W.C., Wu, T.Y.: Exploring types and characteristics of product forms. International Journal of Design 1(1), 3-14 (2007)

2. Desmet, P.M.A., Hekkert, P.: Framework of product experience. International Journal of Design 1(1), 57-66 (2007)

3. Edgar, A., Sedgwick, P.: Key Concepts in Cultural Theory. Routldge, NY (1999)

4. Faiola, A.: The Design Enterprise: Rethinking the HCI Education Paradigm. Design Issues 23(3), 30-45 (2007)

5. Handa, R.: Against arbitrariness: Architectural signification in the age of globalization. Design Studies 20(4), 363-380 (1999)

6. Jakobson, R.: Closing Statement: linguistics and poetic. In: Sebeok, T. (ed.) Style and Language, MIT Press, Cambridge (1960)

7. Kapor, M.: A Software Design Manifesto. In: Winograd, T., Bennett, J., DeYoung, L., Hartfield, B. (eds.) Bringing Design to Software, Addison Wesley, New York (1996)

8. Kottak, C.P.: Windows on Humanity. McGraw Hill, New York (2005)

9. Lee, K.P.: Design methods for a cross-cultural collaborative design project. In: Redmond, J., Durling, D., de Bono, A. (eds.) Proceedings of Design Research Society International Conference - Futureground. Paper No.135, Monash University, Melbourne (2004)

10. Leong, D., Clark, H.: Culture-based knowledge towards new design thinking and practice A dialogue. Design Issues 19(3), 48-58 (2003)

11. Lin, R.T.: Transforming Taiwan Aboriginal Cultural Features Into Modern Product Design Case Study of Cross Cultural Product Design Model. International Journal of Design 1(2), 45-53 (2007)

12. Lin, R., Cheng, R., Sun, M.-X.: Digital Archive Database for Cultural Product Design. In: Aykin, N. (ed.) HCII 2007. LNCS, vol. 4559, pp. 154-163. Springer, Heidelberg (2007)

13. Lin, R., Yang, S.-W., Siao, W.-S., Lin, H.-y., Kang, Y.-Y.: Designing "Height" into daily used products - A case study of universal design. In: Stephanidis, C. (ed.) HCI 2007. LNCS, vol. 4554, pp. 207-216. Springer, Heidelberg (2007)

14. Lin, R.T., Kreifeldt, J.G.: Ergonomics in Wearable Computer. International Journal of Industrial Ergonomics, Special Issue: Ergonomics in Product Design 27, 259-269 (2001)

15. Norman, D.A.: The Psychology of Everyday Things. Basic Books, New York (1988)

16. Norman, D.A.: Emotional Design. Basic Books, New York (2004)

17. Preece, J., Rogers, Y., Sharp, H., Benyon, D., Holland, S., Carey, T.: Human-computer interaction. Addison Wesley, New York (1994)

18. Roberts, M.: Border crossing - The role of design research. International Product Development in AIGA Journal of Interaction Design Education 3(2), 29-39 (2001)

19. Schein, M.: The corporate culture survival guide. Bass Jossey, San Francisco (1999)

20. Schütte, R.: Developing an Expert Program Software for Kansei Engineering. Linköping University, Sweden (2006)

21. Shneiderman, B.: Leonardo's Laptop: Human Needs and the New Computing Technologies. MIT Press, Cambridge, MA (2002) 